\title{
Materialidades discursivas e o funcionamento da ideologia e do inconsciente na produção de sentidos
}

Belmira Magalhães (UFAL) Helson Flávio da Silva Sobrinho (UFAL)

\section{Resumo}

Filiados à perspectiva da Análise do Discurso $(A D)$, compreendemos o sujeito do discurso enquanto ser radicalmente histórico - constituído pela linguagem, pela ideologia e afetado pelo inconsciente. Essa tomada de posição impõe levar em consideração as condições de produção na sociedade capitalista, como a exploração do trabalho e a produção-consumo de mercadorias. Sendo o discurso materialidade da ideologia, ele é sempre uma prática histórica, e seu funcionamento revela os gestos de interpretação dos sujeitos que atuam nas práticas sociais postas como necessárias à reprodução/transformação das relações de produção. Assim, pressupondo o funcionamento da ideologia e do inconsciente na produção dos efeitos de sentidos, este artigo analisa propagandas de empresas de telefonia móvel/celular. Trata-se de vídeos apresentados nas datas comemorativas do Dia das Mães e do Dia dos Pais. Nesta análise, compreende-se que essas propagandas põem em funcionamento a ideologia dominante, que "naturaliza", mediante os efeitos de evidência, os lugares das mulheres e dos homens. Esse funcionamento é essencialmente atravessado pelas formações inconscientes capazes de corroborar a eficácia dos efeitos de sentido. Portanto, tais materialidades discursivas mobilizam uma rede de sentidos que revela um processo discursivo, $o$ qual retoma e ressignifica os sentidos inscritos no discurso do Outro, confluindo na realização dos interesses de um "sujeito consumidor" que "faz suas escolhas" com "aparente" conhecimento de causa.

Palavras-chave: Discurso; ideologia; inconsciente; sentido; história. 


\section{Introdução}

A proposta deste artigo é refletir sobre os discursos na contemporaneidade que circulam no cotidiano e evidenciam sentidos que aparentam "ratificar" os lugares e posições sociais dos sujeitos, considerando-os, em sua imediaticidade, como "naturais". Entretanto, estes, na essência de seu funcionamento, trazem o caráter material e histórico que manifesta a contraditoriedade - tanto do sujeito contemporâneo quanto do "seu" discurso. Para nós, o efeito desse entrecruzamento contraditório de sujeitos e sentidos nas materialidades históricas discursivas atua no movimento dialético do real, em sua totalidade complexa, na dinâmica de reprodução/transformação das relações sociais.

Apresentar essa discussão, dependendo da direção político-analítica, tem implicações teóricas decisivas na Análise do Discurso de linha pecheutiana e chega mesmo a ser algo desafiador. Afirmar que o sujeito faz história atuando nas práticas sociais e sofre o peso das determinações sócio-históricas, é certamente algo polêmico na $\mathrm{AD}$, mas não impossível de ser abordado. Trata-se de uma questão crucial, visto que é imprescindível sair da imediaticidade da análise e buscar a totalidade das questões, a fim de dar continuidade ao caráter teórico e político da Análise do Discurso, sobretudo visando à crítica radical da sociedade capitalista e à superação das relações de exploração.

Desse modo, abordaremos, na primeira parte do presente texto a questão da relação objetividade e subjetividade, adotando um posicionamento radical na teoria materialista do discurso. Em seguida, encaminharemos às análises das materialidades discursivas, procurando desvelar, no funcionamento do discurso, o caráter material do sentido e dos sujeitos em sua concretude radicalmente histórica.

\section{A relação entre objetividade e subjetividade na teoria materialista do discurso}

A Análise do Discurso (AD) da linha de Michel Pêcheux tem caráter teórico e político, pois sua história, assim como a de qualquer ciência, está atrelada às relações de produção/reprodução/ transformação, ou seja, relações de base econômica e de cunho político, inscritas no movimento dialético do real sócio-histórico.

É tomando essa especificidade que Pêcheux critica o idealismo em Linguística - que, à sua época, tratava de um sujeito intencional tido como "dono do sentido" e "senhor de sua morada" -, bem como ao estruturalismo, ao gerativismo, ao funcionalismo e ao marxismo mecanicista. Questões de caráter político-científico não faltaram em seus trabalhos, e isso foi um passo decisivo para pensar a problemática da relação entre objetividade e subjetividade na articulação do quadro teórico da Análise do Discurso. Pêcheux e Fuchs, no texto intitulado "A propósito da Análise 
Automática do Discurso: atualização e perspectivas", apresentam o quadro teórico da $\mathrm{AD}$, com a articulação de três regiões do conhecimento:

1. o materialismo histórico, como teoria das formações sociais e de suas transformações, compreendida aí a teoria das ideologias;

2. a linguística, como teoria dos mecanismos sintáticos e dos processos de enunciação ao mesmo tempo;

3. a teoria do discurso, como teoria da determinação histórica dos processos semânticos. (1997, p. 163 e 164)

Não poderia ficar de fora dessa citação a passagem em que Pêcheux e Fuchs fazem uma importante ressalva: "convém explicitar ainda que estas três regiões são, de certo modo, atravessadas e articuladas por uma teoria da subjetividade (de natureza psicanalítica)" (PECCHEUX \& FUCHS, 1997, p. 164). Portanto, Pêcheux propunha trabalhar as contradições dessas áreas de conhecimento, vinculando com propriedade o caráter teórico e político desse gesto. Diante desse quadro teórico faremos nossas considerações com base no entremeio das contradições, pois deve haver uma hierarquia nesse construto teórico.

Primeiramente, o Materialismo Histórico - a necessária compreensão das formações sociais, seu movimento dialético de transformação, e a ideologia em seu funcionamento. Esse lugar no materialismo histórico na $\mathrm{AD}$ não dispensa a efetiva consideração das condições de produção. Estas são as relações de produção/ reprodução/transformação das relações sociais que, numa sociedade regida pelo Capital, toma caráter de relações de exploração do trabalho na produção-consumo de mercadorias, manifestadas em interesses e conflitos de classes.

A ideologia cumpre uma determinada função social, pois enquanto produção social age sobre os sujeitos, orientando suas ações para a manutenção e/ou transformação das relações de produção. Esse funcionamento é produzido pelas práticas históricas dos sujeitos, que constituem individualidades como fonte das relações sociais, traduzidas, muitas vezes, em dizeres que afirmam que "você pode", "eu posso", "você consegue" (MAGALHÃES, 2013). Para tanto, silenciam-se as contradições sociais que inviabilizam que todos efetivamente "possam", ou apagando determinações sociais de raiz e base material que não apenas diferenciam, mas dividem em relações desiguais e contraditórias os sujeitos, os objetos e os sentidos.

Para que essas questões apareçam, elas também se materializam na língua em sua relativa autonomia, pois a linguagem não é transparente, o sentido nunca é estabilizado e não tem caráter "literal". A ordem da língua e a ordem histórica se imbricam nas relações entre os sujeitos (ORLANDI, 1999). Uma língua capaz de 
falha, de equívoco, que permite aos sujeitos jogar com e sobre as regras, mas, sobretudo, dizer, repetir, parafrasear, metaforizar, no jogo incessante de significar o mundo, produzindo gestos de interpretação que partem do real e nele atuam.

Nessa intricada relação, a semântica, tida como ponto nodal das contradições em Linguística - que segundo Pêcheux (1997) tem a ver com as formações sociais -, convoca uma teoria que exige pensar as determinações históricas dos processos de significação. Para compreender isso, tomemos como exemplo, nas sociedades contemporâneas, o movimento de transferência/deriva da noção de direitos sociais para direitos de consumidor (código do consumidor/definição de cidadão nas sociedades capitalistas contemporâneas). Discursos que fazem significar o consumo como forma de "suprir" as frustrações, "realizar" os "desejos" dos sujeitos, e têm atuado como mediadores da afetividade e dos laços sociais.

Chegamos assim à Psicanálise, na busca de pensar a questão da teoria da subjetividade de natureza não subjetivista. Tratar do atravessamento do inconsciente também exige pensá-lo como histórico, já que o Ser Social dotado de consciência e inconsciente é um sujeito radicalmente histórico, que busca dizer, mas não tem "controle total" do que diz. Algo sempre irrompe e desestabiliza o dito, mostrando o que foi inculcado na formação inconsciente e que faz parte da memória histórica.

Numa célebre síntese de Pêcheux, podemos visualizar o teor dessa complexa articulação:

o recalque inconsciente e o assujeitamento ideológico estão materialmente ligados, sem estar confundidos, no interior do que se poderia designar como o processo do Significante na interpelação e na identificação, processo pelo qual se realiza o que chamamos as condições ideológicas da reprodução/transformação das relações de produção. (PÊCHEUX, 1997, p. 133, grifos do autor)

Nesse ponto salientamos que o Sujeito do Discurso toma sempre uma forma-sujeito. No caso em estudo, toma a forma-sujeito do capitalismo, manifestando e vivenciando as contraditoriedades que surgem através dos deslizes, equívocos que a própria língua permite realizar, mas que apenas as determinações históricas possibilitam significar em direção "certa" ou "errada".

Há, portanto, a necessidade de considerar a relação entre objetividade e subjetividade, pois todo discurso carrega em si as contradições das relações sociais. É desse ponto de vista que trabalharemos a AD, ou seja, no entremeio da práxis social e discursiva vinculada à atividade humano-material.

\section{As "escolhas" fazem o sujeito "do" discurso - um efeito de determinação}

A questão de se "as escolhas fazem" o sujeito "do" discurso diz respeito à relação objetividade e subjetividade. $\mathrm{O}$ critério aqui não é uma subjetividade independente que "tudo pode", nem uma 
objetividade desvinculada da atividade do sujeito. Trata-se de uma relação dialética em que a subjetividade pode atuar no real, mas o critério de verdade é o objeto. A relação do sujeito com o real sócio-histórico é determinante tanto de sua subjetividade como da própria objetividade. E o trabalho, em seu caráter ontológico, funda essa relação e constitui as subjetividades na imbricação (consciência e inconsciente, língua, ideologia e história). Em síntese, consiste numa práxis social desenvolvida pelos sujeitos e para os sujeitos, algo que não existe na natureza.

Como diz Lukács (1997), a ideologia tem como função efetivar, na práxis, as ideias necessárias ao desenvolvimento social (determinadas pelas relações de produção). Para isso precisa, desde o início do desenvolvimento do sujeito, lançar mão da instituição familiar como a primeira instância determinante na constituição do sujeito e, nesse sentido, aquela que marcará o restante da vida de cada indivíduo. Essas marcas definem a base da individualidade de cada um, pois estarão recalcadas na estrutura da subjetividade. A forma como cada sujeito lidará com esse processo de ser dito pelo Outro e a forma como se estruturará sua imagem a partir desses dizeres (Lacan) serão fundantes para a estrutura psíquica de cada indivíduo (FREUD, 1972).

Contudo, é preciso destacar que a família também é uma instituição histórica, já que, antes do nascimento, os seres sociais são submetidos à ação ideológica. Costumeiramente, nas sociedades modernas capitalistas, essa primeira abordagem é feita através dos membros da família nuclear. Inculcações sobre o lugar e o papel de homens e mulheres na sociedade são ditadas ao indivíduo pelas "escolhas" que a família realiza de roupas, quartos, nomes etc., assim como as expectativas, esperanças, objetivos, sonhos e projetos que os adultos têm em relação ao novo ser.

Sob essas mediações que fazem as inculcações de determinados valores e formas de consciência na constituição dos sujeitos, funcionam os efeitos da divisão social do trabalho (material e espiritual). Como diz Pêcheux "todo processo discursivo se inscreve numa relação ideológica de classes" (1997, p. 92). Tudo isso participará da formação do inconsciente, e algumas dessas marcas podem ser até ressignificadas, mas nunca abolidas da estruturação inconsciente do sujeito. No entanto, é importante frisar que esse processo, embora oriundo de relações sociais que afetam a todos, é recebido de forma particular nas formações inconscientes. Isso faz com que cada sujeito reelabore de forma relativamente diferente as "mesmas" práxis ideológicas.

Nesse sentido, precisamos fazer um resgate do ser consciente, porquanto não há atividade humana sem consciência. Desse modo, o materialismo dialético afirma que o "homem não é meramente um ser racional ou um ser dotado de alma ou um ser a quem se atribui algum princípio, mas o homem é atividade" 
(CHASIN, 1999, p. 110). Atividadee, portanto, práxis, ou seja: o pensar exige objetivo visando atuar nos processos de sociabilidade.

Embora se dê ênfase à subjetividade como transformadora, para o materialismo histórico-dialético os critérios de verdade são sempre objetivos, pois a subjetividade tem o poder de captar e mudar a realidade, mas ela depende da lógica dessa mesma realidade para conseguir realizar essas duas atividades especificamente humanas.

A subjetividade é determinada pelas relações sociais de seu tempo histórico. Nas palavras de Marx: "não é a consciência dos homens que determina o seu ser, mas, ao contrário, é o seu ser social que determina sua consciência" (MARX, 1996, p. 52). No entanto, nenhuma realidade oferece apenas uma única opção, e nesse espaço de "escolhas" possíveis a subjetividade exerce a capacidade de produzir o novo em todas as práticas humanas, inclusive as práticas discursivas.

Assim, levando em consideração a experiência histórica nas sociedades modernas, submetidas à lógica do capital, nenhuma subjetividade escapará da determinação do mercado, da lógica da mercadoria. Como diz Lukács:

No século passado e no começo deste, o capitalismo controlava a produção e explorava o trabalhador, arrancando-lhe a mais-valia, no âmbito da produção. Atualmente, o capitalismo estendeu seu controle ao consumo. Através da publicidade, cuja força manipulatória cresce dia a dia, o capitalismo fomenta necessidades artificiais e, pelo controle delas, controla o mecanismo das compras e vendas, contorna as crises geradas pelo desequilíbrio do mercado. Com isso, o trabalhador não é explorado apenas como trabalhador; é explorado também como consumidor. (LUKÁCS, 1978b, p. 23)

Para que essa lógica de exploração sobre o sujeito consumidor seja eficiente, os mecanismos ideológicos se utilizam necessariamente de todas as formas de convencimento, principalmente aquelas que se dirigem a aspectos emocionais dos sujeitos, como os voltados às relações familiares, a exemplo do que veremos na propaganda analisada mais à frente. Mas para que haja sucesso, para que o efeito pretendido pelo sujeito do discurso atinja seu alvo, os sujeitos "consumidores", esses precisam já ter sido afetados pelos efeitos do pré-construído e da memória discursiva. Ou seja, devem ser constituídos como sujeitos estranhados, o que os configurará como seres divididos e alienados, visto que

é a alienação (e o estranhamento) interna ao próprio sujeito, portanto, a cisão do sujeito mesmo que está implicada em sua relação alienada e estranhada com outros sujeitos. E mais ainda: que o critério interno ao sujeito, portanto a dimensão da subjetividade envolvida em sua relação alienada e estranhada com os outros, é aquela em que o próprio sujeito se encontra como trabalhador, quer dizer, como força de trabalho, como mercadoria. (SILVEIRA, 1989, p. 52, grifos do autor) 
Esse sujeito se percebe na imediaticidade como consumidor, mas esquece que tem trabalhado, estranhamente, tão só para exercer suas tarefas e para poder "consumir". A família contemporânea, como em qualquer outro sistema, precisa reproduzir esse sujeito, e a propaganda que será analisada mostrará como a ideologia de mercado necessita estar sempre a reforçar essas funções sociais. Os indivíduos no modo de produção capitalista serão classificados de acordo com a quantidade e a qualidade do que possuem e podem ter (comprar). Ou seja: precisam ser como as propagandas dizem que devem ser (ou ter). Segundo Silveira,

nas próprias subjetividades está plasmada, soldada, marcada, de uma maneira profunda, a diferença que, por excelência, torna os indivíduos, sob o capitalismo, indiferentes: a diferença quantitativa, a comparabilidade quantitativa de si mesmo, dos outros e do conjunto das relações: a universalidade da alienação. (SILVEIRA, 1989, p. 63, grifos do autor)

Levando em consideração o funcionamento da ideologia, é preciso destacar que sua potência só se realiza na instância do inconsciente. É que só haverá eficácia se o discurso conseguir, mediante algum significante, na representação do sujeito para outro significante, mobilizar em cada indivíduo e em todos que se pretende atingir, o desejo de ocupar aquele lugar das "personagens" apresentadas nas propagandas. Hoje em dia, com as novas tecnologias médicas, antes mesmo do nascimento os indivíduos já são referidos como homem e como mulher, como futuros pais e futuras mães. O que a propaganda faz é atualizar esses papéis e convocar pais e mães modernos, mais que isso, "bons consumidores", para funcionar como exemplos às futuras gerações, quase um "protótipo" de sujeitos consumidores.

$\mathrm{Na}$ análise que apresentaremos a partir de agora, vamos tomar a materialidade discursiva como materialidade da ideologia. Serão analisados dois vídeos de propagandas de telefonia móvel/celular (mais especificamente, da empresa de telefonia Claro) apresentadas nas datas comemorativas do Dia das Mães (2009) e do Dia dos Pais (2007).

Direcionando o olhar para o vídeo do Dia das Mães (maio/2009), observamos que ele apresenta uma mulher/mãe cuidando dos filhos em casa, no parque, levando-os ou trazendo-os da escola. Segue abaixo a transcrição dos dizeres:

Você conhece alguma pessoa que acorda de madrugada, feliz?

Que dá duro para juntar dinheiro e não gasta com ela? Que pode estar cheia de problemas, mas para tudo para escutar os seus?

Que trabalha o dia inteiro e quando chega em casa trabalha mais, sorrindo?

Bom, se você conhece alguma pessoa assim, dê um Claro, porque ela merece. 
Ela fala $10 \times$ mais os minutos do plano.

Suas escolhas fazem você mãe.

(Claro, Dia das Mães/2009).

As cenas mostram o estabilizado em relação à posição da mulher na sociedade, mais do que o discurso verbal. $\mathrm{O}$ que reforça o efeito do sentido pretendido são as imagens da mulher, em diferentes situações de trabalho: "que trabalha o dia inteiro e quando chega em casa trabalha mais", sempre feliz e sorridente. A maternidade, atividade trabalhosa, é apresentada como a única forma de "tornar"|"fazer" as mulheres felizes em detrimento das outras atividades exercidas pela mulher moderna. Vale ressaltar também que a mulher na propaganda é jovem, com o padrão de beleza dominante, magra, aparentemente bem-sucedida, etc. Por isso deve receber como forma de afeto não um beijo ou um abraço, mas um aparelho celular, que servirá de instrumento para continuar sua labuta e facilitar todas as atividades que ela realiza falando "10 x mais", porque "ela merece".
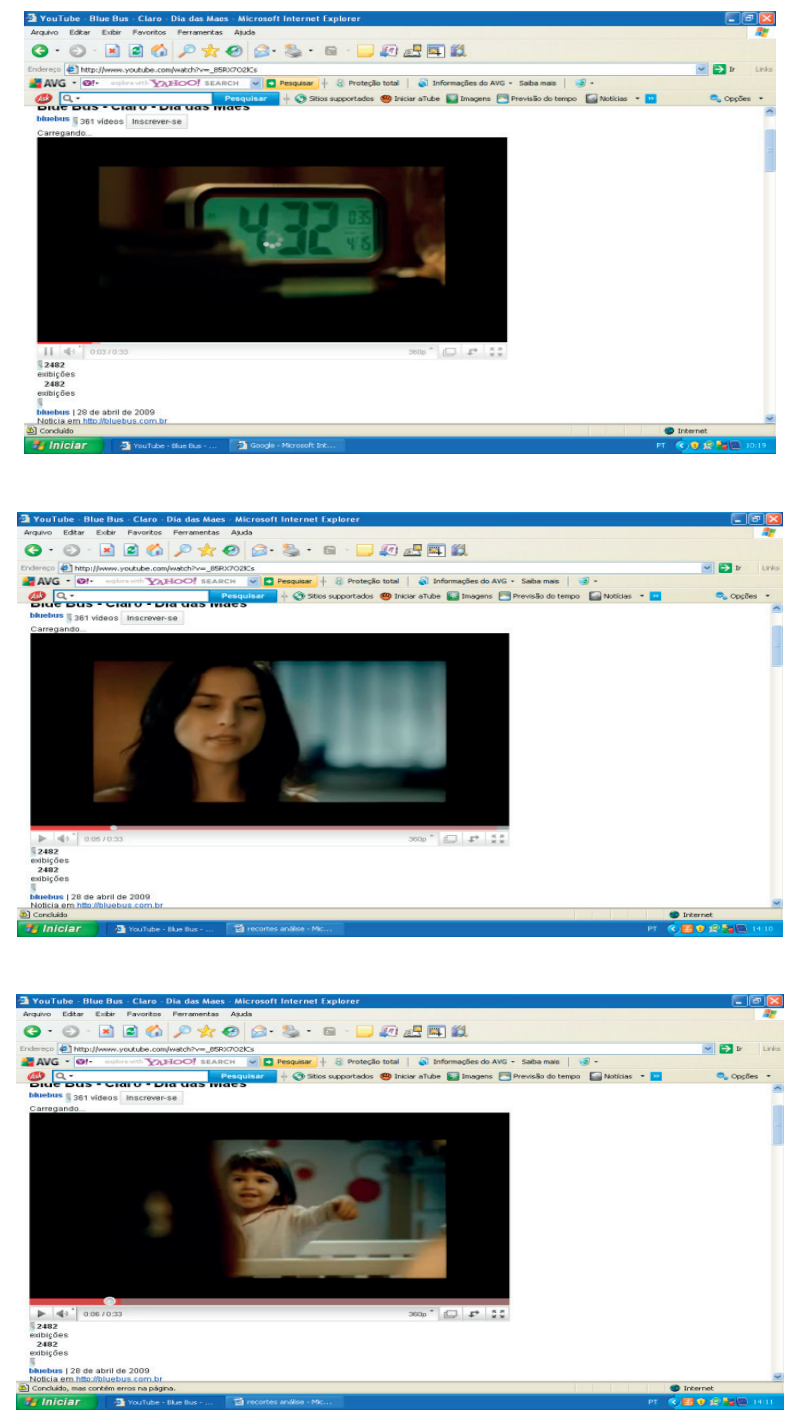

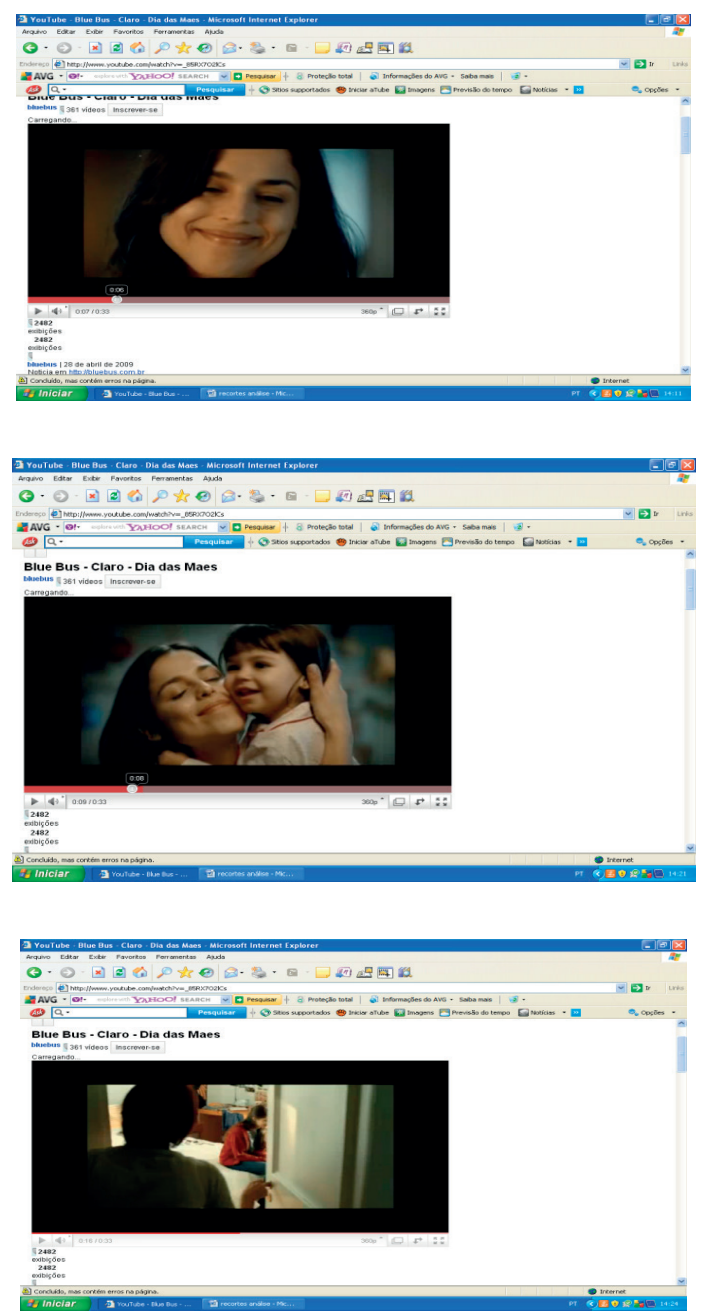

(Propaganda Claro, Dia das Mães)
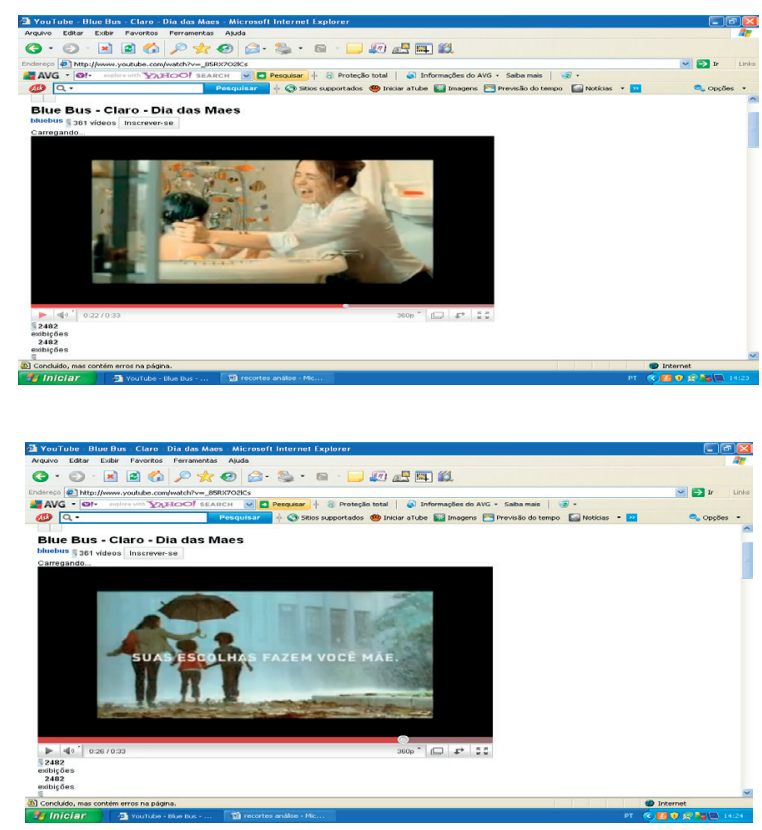


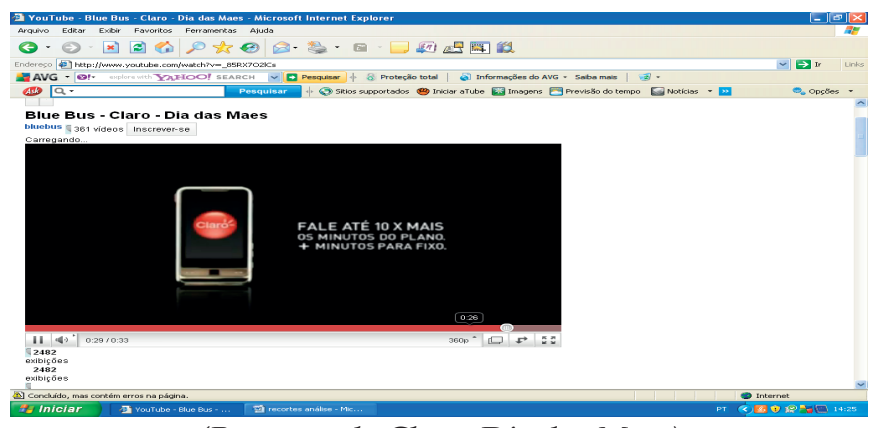

(Propaganda Claro, Dia das Mães)

Esse discurso publicitário enlaça as mulheres nas contradições das relações sociais, inculcando/ internalizando lugares e papéis preestabelecidos. Esse discurso que afirma que "suas escolhas fazem você mãe" produz o efeito de repetição da memória discursiva dos papéis que cada gênero na sociedade deve assumir para cumprir sua função social.

No segundo filme, veiculado no mês do Dia dos Pais (agosto de 2007), podemos observar que ele aparentemente desloca o lugar do sujeito discursivo ao mostrar que no "afeto" homens e mulheres são iguais. Na propaganda, aparece uma menina "controlando" o seu texto, reescrevendo o seu dizer e redirecionando a "mesma" carta que foi escrita anteriormente para a mãe. Agora ela é destinada ao pai, ou seja, a mesma carta parece servir igualmente para dizer sobre o amor que a criança nutre pela mãe e pelo pai. As imagens mostram uma criança feliz e moderna, que usa com desenvoltura o aparelho celular, domina o seu texto e reformula o seu dizer.

Segue a transcrição do vídeo:

Pai, você é a pessoa mais importante que existe pra mim. (...) Te amo!

Essa carta eu escrevi para mamãe, mas agora tô escrevendo pra você.

É pra mostrar que eu amo você que nem eu amo a mamãe.

Mas ó, não vai chorar, que isso é coisa de MÃE!

Dias dos Pais Claro. Seu pai fala o dobro de minutos e ainda ganha um Motorola A 1200.

Claro. A vida na sua mão.

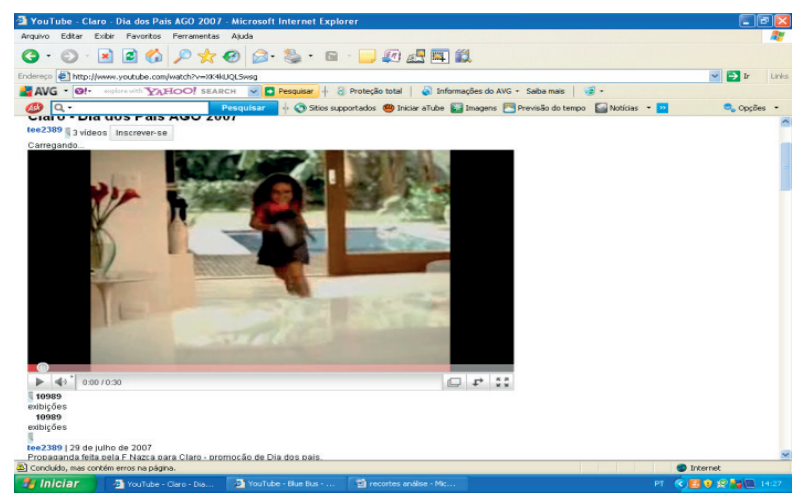



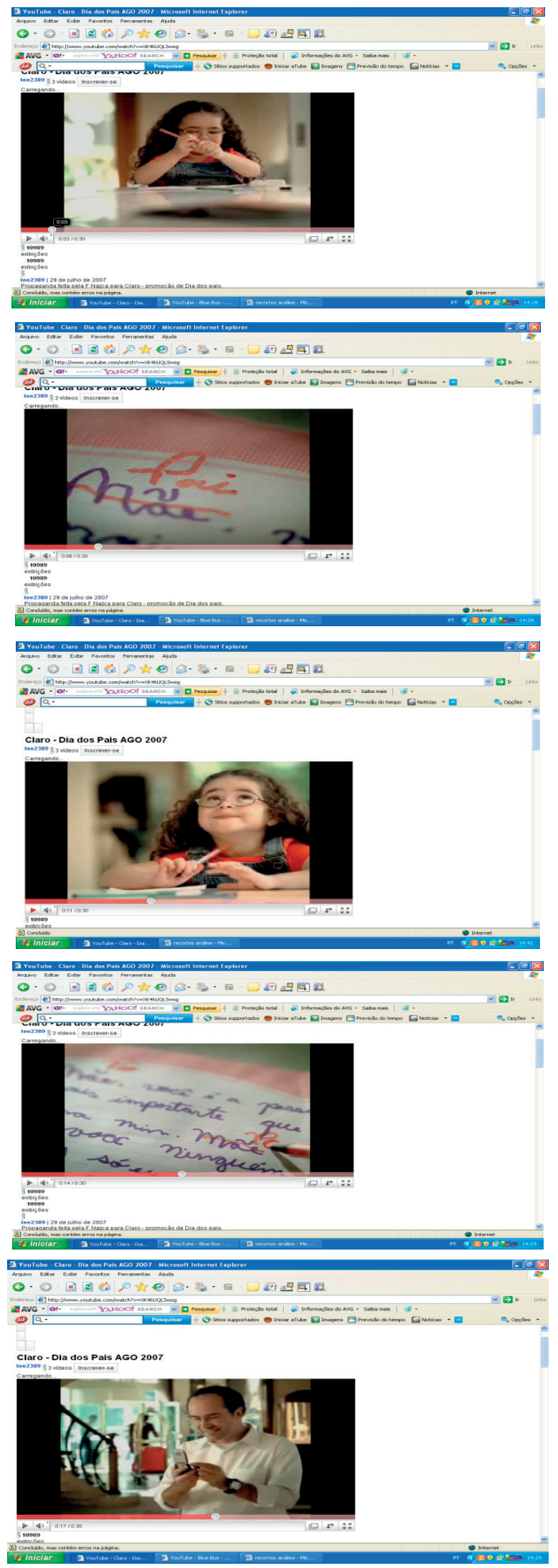

(Propaganda Claro, Dia dos Pais) 
Mais sutil que o primeiro vídeo, a presença do pai na propaganda recapitula as diferenças (espaço privado e espaço público/ a casa e a rua/ o trabalho assalariado e o trabalho doméstico não pago/ a mulher em sua dupla ou tripla jornada). O sujeito da enunciação insere-se na materialidade discursiva para reforçar o que já estava dado pelo lugar onde o pai estava, ou seja, fora de casa. O pai aparece fora do espaço doméstico, a receber uma mensagem de carinho via celular. $\mathrm{O}$ amor é o mesmo, o presente é o mesmo, mas homens e mulheres (pais e mães) não reagem da mesma maneira. O pai se emociona, mas ri. O lugar do choro é reservado às mulheres, como diz a propaganda: "Mas ó, não vai chorar, que isso é coisa de mãe".

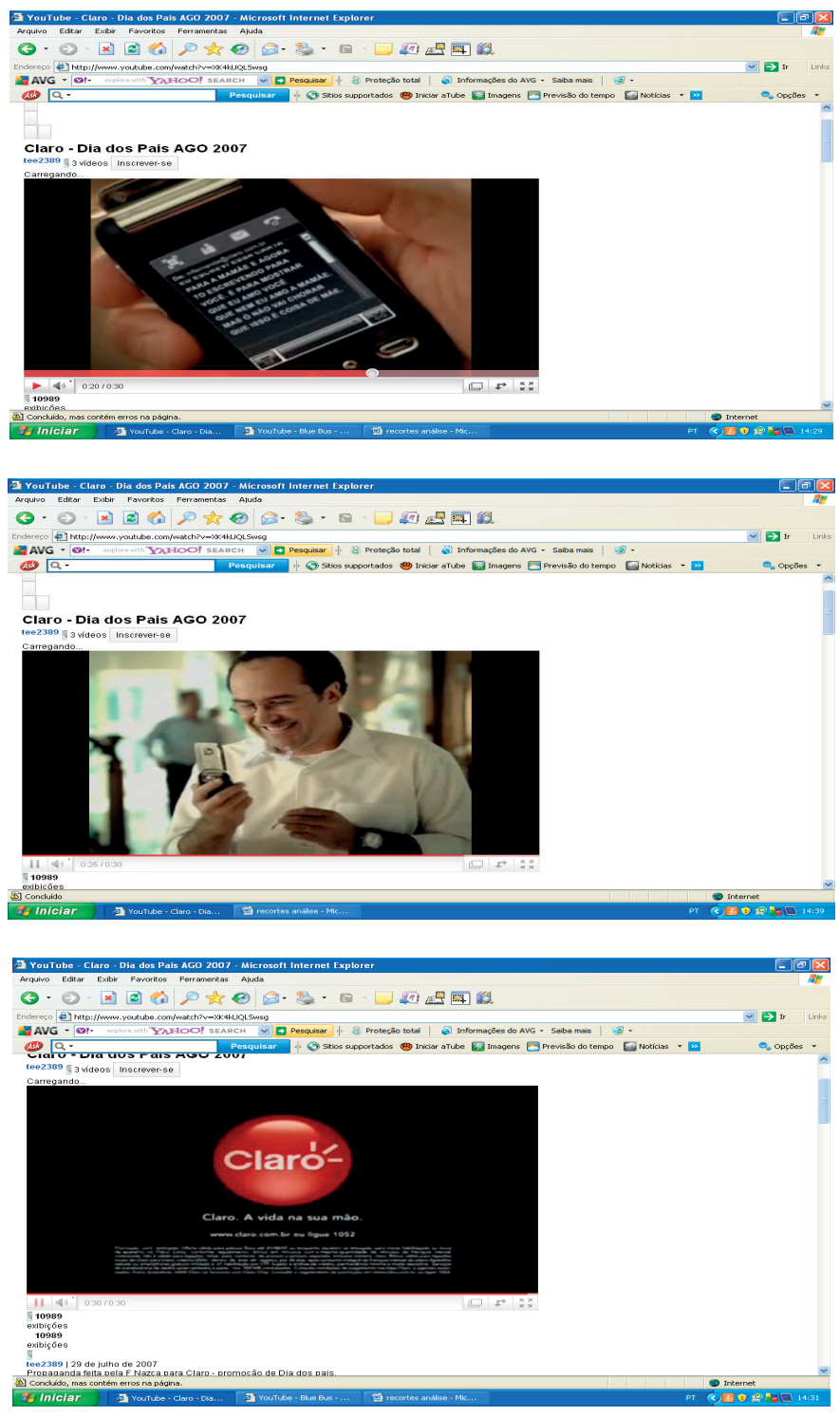

(Propaganda Claro, Dia dos Pais) 
O que vemos a partir dessas materialidades discursivas confirma o que diz Pêcheux:

a marca do inconsciente como "discurso do Outro" designa no sujeito a presença eficaz do "Sujeito", que faz com que todo sujeito "funcione", isto é, tome posição, "em total consciência e em total liberdade", tome iniciativas pelas quais se torna "responsável" como autor de seus atos, etc. (PÊCHEUX, 1997, p. 171)

As duas materialidades discursivas estabelecem as relações afetivas mediadas pelo produto de consumo (aparelho celular). Nas duas propagandas, a lógica capitalista que precisa baratear a socialização e manter a reprodução do trabalhador sem custos adicionais, ao manter a mulher e o homem em seus espaços "naturais". Desse modo, faz funcionar a ideologia patriarcal, diferenciando homens e mulheres e, ao mesmo tempo, suturando essa diferença por meio de uma injunção ideológica.

Essa forma de relação do sujeito com a lei (cultura), que parece "fixar" os sujeitos na ordem do social, é utilizada desde o nascimento do ser social. Assim, inculcará essas posições diferentes, de homens e mulheres, para o resto de suas vidas:

É nesse reconhecimento que o sujeito se "esquece" das determinações que o colocaram no lugar que ele ocupa - entendamos que, sendo "sempre-já" sujeito, ele "sempre-já" se esqueceu das determinações que o constituem como tal. (PÊCHEUX, 1997, p. 170)

As mulheres esforçam-se para ser boas filhas, boas mães, boas esposas e boas profissionais, ao custo de uma culpabilização que as coloca quase sempre em estado de ansiedade. Os homens têm de ser os provedores, mesmo que isso implique não participar do cotidiano de sua família e perder momentos importantes do desenvolvimento dos filhos. Sua ausência é sempre justificada porquanto ocorre para que ele possa dar mais conforto aos seus, e isto se traduz em possibilidades de oferecer mais consumo nas relações com as mercadorias.

Vale ressaltar que para Pêcheux (1997) a identificação discursiva se dá pelas filiações sócio-históricas (formação ideológica e formação discursiva), admitindo-se uma agitação no interior destas. A práxis torna possível sempre, de forma consciente e inconsciente, o deslocamento do sujeito. Haverá sempre a possibilidade do desvio, do equívoco (língua/história/ideologia/ inconsciente). $\mathrm{O}$ discurso não é uma construção independente das relações sociais e do condicionamento inconsciente. Assim, o fazer discursivo é uma práxis humana que só pode ser compreendida a partir do entendimento das contradições sociais que possibilitaram sua objetivação e de como cada indivíduo processa, no aparelho psíquico, essas determinações.

Marx, na introdução do texto "Para crítica da economia política", afirma que "na produção social da própria vida, os homens 
contraem relações determinadas, necessárias e independentes de sua vontade, relações de produção estas que correspondem a uma etapa determinada de desenvolvimento das suas forças produtivas materiais" (MARX, 1996, p. 52). Ao avançarmos na questão colocada no início desta análise, podemos considerar também que os sujeitos "fazem suas escolhas", mas as fazem determinados pelas relações sócio-históricas nas quais estão inseridos e em que são sujeitos atuantes. Escolhas que determinam (mas nunca de modo mecânico) o sujeito em face das alternativas históricas possíveis de reprodução/transformação/revolução das relações sociais.

Segundo Lukács:

Toda práxis social, se considerarmos o trabalho como seu modelo, contém em si esse caráter contraditório. Por um lado, a práxis é uma decisão entre alternativas, já que todo indivíduo singular, sempre que faz algo, deve decidir se o faz ou não. Todo ato social, portanto, surge de uma decisão entre alternativas acerca de posições teleológicas futuras. A necessidade social só se pode afirmar por meio da pressão que exerce sobre os indivíduos (frequentemente, de maneira anônima), a fim de que as decisões deles tenham uma determinada orientação. Marx delineia corretamente essa condição, dizendo que os homens são impelidos pelas circunstâncias a agir de determinado modo, "sob pena de se arruinarem". Eles devem, em última análise, realizar por si as próprias ações, ainda que frequentemente atuem contra sua própria convicção. (LUKÁCS, 1978a, p. 6)

Como dissemos anteriormente, as sociedades capitalistas são sociedades de classes - conflituosas e de interesses antagônicos. A ideologia da classe dominante busca conseguir seus objetivos; no entanto, durante todo esse processo ocorre um conflito que também repercute diretamente no sujeito que é convocado a ser consumidor, pois nem todos podem alcançar esses objetivos no mercado. Por mais que se esforcem trabalhando, trabalhando mais e se endividando, os produtos são consumidos diferentemente e por pessoas de classes distintas, que desigualmente têm "acesso" a eles, ou melhor, poder de compra sobre as mercadorias. Esses conflitos fazem a ebulição e a criação do novo, sob as mais diferentes formas, que podem até mesmo ser traduzidas em formas de resistência à ideologia dominante, implicando mudanças e transformações revolucionárias.

\section{Considerações finais}

Em nossa análise, compreendemos que essas propagandas põem em funcionamento a ideologia dominante, que diz sobre o lugar "natural" da mulher e do homem na sociedade. Esse funcionamento é essencialmente atravessado pelas formações inconscientes capazes de corroborar a eficácia dos efeitos de sentido.

Os vídeos analisados mobilizam uma rede de sentidos que no seu entrecruzamento (materialidade simbólica, ideologia, in- 
consciente) alcançam e fazem funcionar nos sujeitos os interesses da lógica do capital. Ao assim agirem, revelam um processo discursivo que retoma e ressignifica os sentidos inscritos no discurso do Outro, confluindo na realização dos interesses de um sujeito constituído como consumidor "nato".

Desde o resumo do presente artigo salientamos o papel político da AD. De nossa parte, queremos enfatizar, baseados nas teorias que subsidiaram a importância do gesto analítico de desvelamento do discurso dominante que esse tipo de propaganda quer perpetuar, que os sujeitos nunca são atingidos igualmente, embora a ideologia busque sempre a generalização. Portanto, a continuação dos estudos sobre a linguagem na perspectiva pecheutiana não é apenas a busca de difusão de uma nova forma de entender a língua e a linguagem em geral. Trata-se, sobretudo, de uma forma de efetivar um ato político de confronto com as posições discursivas que propugnam a "neutralidade" da ciência, criando obstáculos para os próprios sujeitos se inscreverem em outras redes de significações, a fim de efetivamente intervirem nas relações sociais.

\begin{abstract}
Affiliated to the perspective Speech's Analysis (SA), we understand speech's subject as being radically historical-constituted by the language, ideology and affected by the unconscious. This statement of position imposes take into consideration production's conditions in capitalist society, such as the exploration of labor and the production-consumption of commodities. Being the speech ideology's materiality, it is always a historical practice and its operation reveals interpretation's gestures of the subjects acting in social practices put as necessary to reproduction / transformation of production relations. Thus, presupposing the working of ideology and of unconscious in the production of sense effects, this article analyzes advertisements for mobile phone companies / mobile. They are presented videos in celebrations dates about Mothers' Day and Fathers' Day. In our analysis, we understand that these advertisements put operating the dominant ideology that "naturalizes", through the evidence's effects, the places of women and of men. This operation is essentially crossed by unconscious formations able to confirm with the effectiveness of sense effects. Therefore, these discursive materialities mobilize a network of sense that, in their intersection (symbolic materiality,
\end{abstract}


ideology, unconscious), achieve and make working for and by subject the interests of the logic of capital, revealing a discursive process that returns and resignify the sense enrolled in the Other's speech to converge in the realization of the interests of a "subject consumer" that "makes your choices" with "apparent" knowledge of cause.

Keywords: Speech; ideology; unconscious; sense; history.

\section{REFERÊNCIAS}

CALIGARIS, Contardo. Crônicas do individualismo cotidiano. São Paulo: Editora Ática, 1996.

DUFOUR, Danny-Robert. A arte de reduzir as cabeças: sobre a nova servidão na sociedade ultraliberal. Rio de Janeiro: Companhia de Freud, 2007.

LACAN, Jacques. Escritos. Rio de Janeiro: Jorge Zahar Editor, 1998. LEBRUN, Jean-Pierre. A perversão comum: viver juntos sem o outro. Rio de Janeiro: Companhia de Freud, 2008.

LUKÁCS, Georg. As bases ontológicas do pensamento e da atividade do homem. In: Revista Temas. São Paulo, ciências humanas, $\mathrm{n}^{\mathrm{o}} 4$, 1978a.

LUKÁCS, Georg. A autocrítica do Marxismo. In: Revista Temas. São Paulo, ciências humanas, no 4, 1978b.

LUKÁCS, Georg. O Trabalho. Tradução de Ivo Tonet. Maceió, 1997, mímeo.

MAGALHÃES, Belmira. As marcas do corpo contando a história. Maceió: Edufal, 2005.

MALDIDIER, Denise. A inquietação do discurso: (re)ler Michel Pêcheux hoje. Campinas: Pontes, 2003.

MARIANI, Bethania. Uma análise do discurso desejante. In: NAVARRO, Pedro (org.). O discurso nos dominios da linguagem e da história. São Paulo: Claraluz, 2008.

MARX, Karl. Para a crítica da economia política. São Paulo: Nova Cultural, 1996.

ORLANDI, Eni. Análise de discurso: princípios e procedimentos. Campinas: Pontes, 1999.

PÊCHEUX, M.; FUCHS, C. A propósito da Análise Automática do Discurso: atualização e perspectivas. In: GADET, F.; HAK, T. (Orgs.). Por uma análise automática do discurso: uma introdução à obra de Michel Pêcheux. $3^{\text {a }}$ ed. Campinas: editora da Unicamp, 1997. PÊCHEUX, Michel. O Discurso: estrutura ou acontecimento. Campinas: Pontes, 2002. 
PÊCHEUX, Michel. Semântica e Discurso. Campinas: Editora da Unicamp, 1997.

SILVEIRA, Paulo. Da alienação ao fetichismo - formas de subjetivação e de objetivação. In: SILVEIRA, P.; DORAY, B. (Orgs.). Elementos para uma teoria marxista da subjetividade. São Paulo: Vértice, 1989. 